\title{
SUBSÍDIOS PARA ELABORAÇÃO DE UMA PROPOSTA DE CURRÍCULO MÍNIMO PARA A FORMAÇÃO DO ENFERMEIRO
}

\section{INTRODUÇĀO}

O ensino superior no Brasil vem sendo continuamente questionado pela sociedade de modo geral e, particularmente, por uma camada significativa daqueles que compōem a chamada comunidade acadêmica. Nem sempre estes questionamentos guardam identidade entre si, pois não emergem de categorias de análises e perspectivas semelhantes. É quase impossível identificar, no bojo dessas manifestaçōes, uma direcionalidade regular para esse ou aquele aspecto do ensino superior. Percebe-se que o foco das críticas, a depender de sua origem, ou se desloca ou se mantém. Nesse sentido, as discussōes sobre as características, produtividade, qualidade e pertinência técnica, política, social, tecnológica e científica de um determinado curso superior nascem, em geral, entre docentes e discentes, instituiçōes e serviços que absorvem os egressos e, em alguns casos, daqueles que sofrem, de forma direta ou indireta, a intervenção do fazer/pensar que o curso constrói e conforma.

A ampla discussão, avaliação e questionamento atuais sobre o ensino de graduação em enfermagem originaram-se, fundamentalmente, no interior das escolas, das entidades organizativas dos enfermeiros, das instituiçōes e serviços de saúde.

Guardadas as devidas diferenças que embasam e justificam esses questionamentos, depreende-se que os pontos mais freqüentes da pauta de críticas, considerados nucleares no processo que se instalou na comunidade de enfermagem, referem-se:

- à dinânica de formação do enfermeiro e sua inserção no processo de trabalho em saúde;

- à articulação, função e papel do enfermeiro como parte da força de trabalho de saúde e de enfermagem, em particular;

- à pertinência da atual estrutura curricular em orientar a formação do enfermeiro com a capacidade e potencial para intervir de maneira resolutiva, equânime e competente no processo saúde/doença.

No bojo desses questionamentos, várias escolas, serviços e entidades da categoria desencadearam discussões sobre a formação do enfermeiro.

Comissão de Especialistas de Enfermagem e a Comissão de Educação da $\mathrm{ABEn}$, por sua vez, vêm desenvolvendo, nos últimos dois anos, com participação de docentes, discentes e enfermeiros de serviços, seminários (regionais e nacionais) sobre ensino superior de enfermagem, e especificamente, sobre perfil e competência do enfermeiro.
Tais eventos têm evidenciado, ainda que de forma heterogênea, uma insatisfação geral em relação ao atual currículo dos cursos de graduação em enfermagem do País.

Levando em consideração as recomendações dos Seminários, a Comissão de Especialistas de Enfermagem e a Comissão de Educação da ABEn, como coordenadores desse processo de discussão, formularam o Projeto 'Elaboração de Nova Proposta de Currículo Mínimo para Formaçãe do Enfermeiro em Nível de Graduação"'. Como 2.a etapa desse projeto, promoveram uma Oficina de Trabalho, em Brasnia, nos dias 21 e 22 de julho do corrente ano, com objetivo de reunir subsídios para elaboração de uma proposta de Currículo Mínimo para a formação do enfermeiro. Participaram dessa Oficina, além de membros das referidas Comissōes, docentes envolvidos em estudos de currículo e representantes da CAPES e CNPq.

Resultou' desta Oficina o presente documento que, após situar a discussāo que vem sendo desenvolvida nos últimos anos sobre o ensino de enfermagem, apresenta uma análise sintética sobre o Parecer 163/72 e Resolução n.? 04/72 CFE; resgata as recomendaçōes apontadas nos Seminánios; e sugere os pressupostos e princípios que deverão nortear a formulação da nova proposta curricular.

Este documento preliminar está sendo encaminhado às escolas de enfermagem e entidades da categoria com o propósito de ser amplamente discutido por Enfermeiros docentes e de serviço e alunos de enfermagem, com vistas à elaboração de uma proposta curricular por ocasião dos Seminários Regonais previstos. As propostas resultantes desses Seminários serão consolidadas em função da elaboração de uma minuta de proposta curricular que será apresentada e discutida em nível nacional.

\section{O PARECER 163/72 E A RESOLUÇĀO 04/72 DO CONSELHO FEDERAL DE EDUCAÇĀO (CFE)}

A atual estrutura curricular dos cursos de enfermagem no Brasil, expressa no Parecer 163/72 e regulamentada péla Resolução 04/72 - CFE, tem como fator desencadeante a Reforma Universitária definida na Lei 5540/68. Ressalta-se porém que, já na década de 50, a questão do currículo do curso de enfermagem foi alvo e objeto de múltiplas discussões.

\footnotetext{
* Documento preliminar elaborado durante a Oficina de Trabalho promovida pela Comissão de Especialistas (SESU-MEC) e Comissão de Educação da Associação Brasileira de Enfermagem.
} 
O Currículo Mínimo definido em 1962 (Parecer 271/62) nāo conseguiu, contudo, preencher e atender as reivindicações pretendidas. Tanto é que, após a aprovação desse currículo, as "inquietações" dos enfermeiros e das entidades de enfermagem permaneceram e se prolongaram até quando, por exigência da Reforma Universitária, surgiu a oportunidade de formular novo Currículo Mínimo.

A proposta, que entra em vigor em 1973, fragmenta o eixo de formação, compartimentalizando-o em três partes: pré-profissional, tronco profissional comum e habilitações, privilegiando o desenvolvimento do ensino centrado no modelo médico de assistência hospitalar vigente.

A Resolução 04/72 - CFE, num primeiro momento, apresenta como novidade a incorporação de conhecimentos básicos de ciências do comportamento que contemplam o movimento da influência das teorias de administração de enfermagem. Consolida, contudo, o enfoque biológico e, tanto na esfera das ciências biológicas como das ciências do comportamento, limita-se a definir como conteúdo do ciclo básico noções gerais das áreas do conhecimento nele contidas.

Ressalte-se que, no desenvolvimento do tronco pré-profissional, não se prevê a articulação das disciplinas básicas com a especificidade da prática de enfermagem.

No tronco profissional comum, a capacitação de enfermeiros para a intervenção em Saúde Pública se resume a uma abordagem preliminar e insuficiente. Privilegia também o enfoque tecnicista, funcionalista e a assistência ao indivíduo hospitalizado. Nesse sentido, favorece a compreensão dicotomizada de saúde/doença, prevenção/cura, assistência hospitalar/saúde pública, unidade de internação/ambulatório.

Ao fragmentar estruturalmente a formação do enfermeiro, o atual Currículo Mínimo comete um grave equívoco para a formação profissional, que se reflete na prática. Este equívoco se evidencia na subdivisão do curso em habilitações (Enfermagem Médico-Cirúrgica, Enfermagem Obstétrica e Enfermagem de Saúde Pública). Estas habilitações deslocam da formação do enfermeiro conteúdos essenciais, relacionados sobretudo à assistência à mulher e à saúde coletiva, uma vez que o tronco profissional comum tende a se concentrar em conhecimentos da área médico-cirúrgica. Além desta consideração, há de se destacar que, ao longo da aplicação da Resolução 04/72 CFE, as habilitações não estabelecem diferenças de impacto, quer na absorção, quer na inserção do enfermeiro no mercado de trabalho, haja vista, por exemplo, que a existência do enfermeiro habilitado não criou vantagem no plano de cargos e salários, em nível nacional. Ainda é preciso considerar que a questão do caráter opcional das habilitações (tanto para o estudante, quanto para o órgão formador), assim como o caráter de especialização pre- coce configurado na sua aplicação, geram problemas de ordem administrativa, conceitual e ética.

Vale ressaltar que a licenciatura prevista na Resolução 04/72 CFE não se enquadra nestas características. Atende a necessidade do enfermeiro exercer o magistério na área de enfermagem, ao nivel de $10^{\circ}$ e $2^{\circ}$ graus, e lhe permite a inserção em outro espaço de trabalho, essencial no processo de formação das demais categorias que compõem a força de trabalho em enfermagem.

A duração mínima estabelecida nos diplomas legais do CFE, para o curso de enfermagem é de $2.500 \mathrm{hs} / 3$ anos (enfermeiro) e $3.000 \mathrm{hs} / 4$ a 6 anos (habilitaçōes). Esta duração, não obstante pareça uma questão estrutural, tem conseqüências na dinâmica pedagógica dos cursos. Particularmente, as escolas privadas limita-se, em geral, a cumprir o mínimo, acarretando prejuízos ou, pelo menos, um esvaziamento na formulação de uma proposta de currículo pleno. Ademais, em todas as discussões sobre ensino de enfermagem, a duração está sendo considerada como um aspecto a ser redimensionado, tendo em vista a natureza da formulação do enfermeiro e a necessidade de garantir ao estudante espaço para o trabalho individual, para uso da biblioteca, para atividades de pesquisa e participações em suas entidades, dentre outros.

\section{DIFICULDADES APONTADAS NOS SEMINÁRIOS: PERTINÊNCIA AO CURRÍCULO MINIMO OU PLENO}

As dificuldades e recomendações apresentadas nos seminários contemplam problemas de ordem geral pertinentes ao ensino de graduação e à prática de enfermagem, que deverão ser equacionados nos processo de repensar o desenvolvimento dos currículos plenos de cada escola, e outras que indicam diretrizes para a reformulação do currículo mínimo. Os currículos plenos se configuram com a expressão da autonomia de cada curso em decidir a organização do seu ensino diante das especificidades regionais (características epidemiológicas e sanitárias).

Assim sendo, esta organização da formação do enfermeiro em cada escola deve estar mediada por um conjunto de referências, conceitos, estruturas e recursos (humanos, materiais, financeiros e de equipamentos) que permitam produzir um profissional cujo processo de formação tenha aderência com os modelos assistenciais dirigidos ao atendimento de saúde da população.

O currículo mínimo, embora não abranja textualmente estas diretrizes, năo deve negar ou impedir que determinadas referências e determinados conceitos venham a ser contemplados no currículo pleno.

Dada a natureza deste documento, passaremos a ressaltar as questões que, seguramente, serão consolidadas numa nova proposta de Currículo Mínimo.

Os enfermeiros e demais participantes dos se- 
minários reivindicam transformações no Currículo Mínimo que apontam para o seguinte:

a) que se tenha referência a compreensão conjuntural do país e, nesta, o contexto de saúde;

b) que se enfatize o compromisso social do enfermeiro;

c) que se considere a Política Nacional de saúde e os princípios de universalidade, equanimidade, hierarquização, integralidade e resolutividade das açōes de saúde; sional;

d) que se considere a Lei do Exercício Profis-

e) que se considere a necessidade da extinção das habilitações;

f) que se considere a pertinência do aumento da duração do currículo em horas e anos, especificando-se o mínimo de 4 anos para a sua integralização;

g) que se redimensione no rol de matérias o desdobramento das disciplinas, indicando revisão das áreas de ciências humanas, biológicas e de saúde pública.

É preciso ressaltar que caberá a cada curso o encaminhamento das questōes que se referem a definição de marco conceitual da formação ' generalista' do enfermeiro; ao delineamento do seu perfil, explicitando suas funções nas várias áreas de atuação; ao desenvolvimento de trabalho com a comunidade através de uma prática reflexiva permanente; ao delineamento de estratégias estruturais para a operacionalização do ensino (integração docente-assistencial, articulação do tronco pré-profissional com o profissional, articulação com a pesquisa e a pós-graduação, entre outros). Considera-se que tais questões dependem essencialmente das bases conceituais que fundamental a orientação de cada curso no que se refere à compreensão do processo saúde-doença, da assistência de enfermagem, do papel da universidade, das práticas pedagógicas, e outros.

\section{PRESSUPOSTOS E PRINCÍPIOS QUE DEVEM ORIENTAR A FORMULAÇĀO DO CURRÍCULO MÍNIMO PARA OS CURSOS DE GRADUAÇĀO EM ENFER- MAGEM}

Para a compreensão dos pressupostos e princípios que orientam a formulação do Currículo Mínimo é necessário ressaltar os limite que devem presidir as competências do CFE e das escolas.

\subsection{Competências e limites do CFE:}

Cabe ao CFE a definição de conteúdo e duração dos cursos:

a. Quanto ao conteúdo - cabe ao CFE a determinação das matérias, estendendo-se, no máximo, à indicação de disciplinas que compõem cada uma delas sem, contudo, esgotar todos os desdobramentos, possíveis ou necessários, que estas têm ao nível de cada curso.

b. Quanto à duração - a duração definida pelo CFE deve se referir, unicamente, ao total mínimo de horas e ao tempo de integralização, mínimo e máximo, em termos de anos ou semestres letivos. Qualquer especificação absoluta ou percentual de carga horária por matéria/disciplina seria uma extrapolação que pode funcionar, na implementação do Currículo Mínimo, como uma "camisa de força" para os cursos ou para a consolidação de tendências que não contemplem as características regionais ou institucionais.

\subsection{Competências e Limites dos Cursos de Enfermagem:}

a. Quanto ao Conteúdo - se por um lado compete ao CFE a determinação das matérias, por outro, cabe aos cursos de desdobramentos e aprofundamentos possíveis ou necessários em termos dos conhecimentos e procedimentos que a formação do enfermeiro requer.

b. Quanto à duração - apesar do CFE definir a duração mínima e máxima do currículo, os cursos não devem se limitar ao mínimo estabelecido, uma vez que esse parâmetro mínimo funciona como um instrumento que favorece a criação e manutenção de cursos restritivos ou impeditivos do aprofundamento de conhecimento e desenvolvimento de competências técnicas, científicas e políticas, tanto do docente como do discente. Ademais, esse parâmetro mínimo restringe a possibilidade de uma integração mais ampla com os serviços.

c. Quanto aos procedimentos didáticos e metodológicos - a dinânica dos aspectos didáticos e metodológicos no processo de formação profissional é prerrogativa do órgão formador sendo, portanto, inadmissível que os mesmos este jam definidos na estrutura do Currículo Mínimo. A organicidade didático-pedagógica e metodológica do currículo pleno inclui carga horária por disciplina, distribuição da carga horária em teórica e prática, definição da natureza da prática (laboratório, ensino clínico ou estágio curricular supervisionado).

Esses limites e competências do CFE e dos cursos constituem um pressuposto inicial a ser considerado quando se pretende alterar o Currículo Mínimo, uma vez que tem sido constante a indicação de problemas para serem resolvidos pelo CFE quando, na verdade, a sua resolução compete aos cursos, escolas e universidades.

Outros pressupostos devem orientar a formulação de uma nova proposta de Currículo Mínimo para a formação do enfermeiro, tais como:

- A integralidade do currículo deve ser expressa e assegurada na definição e estruturação do conhecimento, de tal forma que os agentes do pro- 
cesso participem das atividades do trabalho em saúde e desenvolvam a assistência de enfermagem de forma articulada com os demais trabalhadores de saúde e de enfermagem.

- O currículo deve assegurar a terminalidade do processo de formação do enfermeiro, excluíndo do nível de gradução a tendência à falsa especialidade. Este pressuposto gera um princípio orientador de um Currículo Mínimo estruturado de forma contínua, com duração em tempo e horas compatíveis com um perfil profissional competente para atual, preferencialmente, rede básica dos serviços de saúde.

Participantes da Oficina de Trabalho:

ABIGAIL MOURA RODRIGUES, Coordenadora da Comissão de Educação da ABEn - CENTRAL.

VILMA DE CARVALHO, Coordenadora da Comissão de Especialistas de Enfermagem/SESu/MEC

ERLITA RODRIGUES DOS SANTOS - ABEn Seção DF - UnB

FRANCISCA NAZARE LIBERALINO C.E. ABEn-CENTRAL - UFRN
IANE NOGUEIRA VALE - C.E. - ABEn-CENTRAL - UNICAMP

JOSICÉLIA DUMÊT FERNANDES - C.E. ABEn-CENTRAL - UFBA

KÊNIA SCHIMIDT REIBNITA - UFSC

MARIA AUXILIADORA CÓRDOVA CHRISTÓFARO - ABEE - UFMG

MARIA DA GLORIA MIOTTO WRIGHT - CNPq MARIA JOSEFINA LEUBA SALUM - EEUSP

NEIDE MARIA FREIRE FERRAZ - CEEnf SESU/MEC

NEUZA APARECIDA RAMOS - CEEnf SESU/MEC

RAIMUNDA MEDEIROS GERMANO - C.E. ABEn-CENTRAL

SIDÊNIA ALVES SIDRÃO ALENCAR MENDES - C.E. - ABEn-CENTRAL - UFF

TELMA RIBEIRO GARCIA - UFAC

THEREZINHA TEIXEIRA VIEIRA - CAPES

YORIKO KAMIYAMA - CEEnf-sesU/mec 